\title{
Successful Treatment of Skull Base Chondroma with Radiation Therapy:
}

\section{About A Case}

A. Bazine ${ }^{1},{ }^{2},{ }^{3},{ }^{4 *}$, M. Elmarjany ${ }^{1}$, M. Benlemlih ${ }^{1}$, A. Maghous ${ }^{1}$, A. Marnouche ${ }^{1}$, M. Houmadi ${ }^{1}$, KH. Andaloussi ${ }^{1}$, KH. Haddadi $^{1}, \mathrm{H}_{\text {. }}$ Sifat $^{1}$, H. Mansouri ${ }^{1}$

${ }^{1}$ Radiotherapy department of Military Instruction Hospital Mohamed V, Rabat, Morocco

${ }^{2}$ Faculty of Medicine and Pharmacy, Fez, Morocco

${ }^{3}$ Sidi Mohamed Ben Abdellah University, Fez, Morocco

${ }^{4}$ Mohamed V University, Rabat, Morocco

DOI: $10.36347 /$ sjmcr.2021.v09i02.004

| Received: 19.01.2021 | Accepted: 01.02.2021 | Published: 10.02.2021

*Corresponding author: A. Bazine

Abstract

Chondroma, a rare benign tumor, occurs in any cartilage of the body. Skull base is an extremely rare location of chondrosarcoma. Complete resection is the treatment of choice and it's not always possible. We report in this work the case of a 60 -year-old woman, who presented with a skull base chondroma treated with radiation therapy alone. With a 2 years follow-up, a marked symptomatology improvement was reported by the patient. On control MRI, tumoral process remained stable. We shed light, through this case, on the place of radiotherapy in the treatment of skull base chondromas.

Keywords: Chondroma, skull base, radiation therapy.

Copyright $(\mathcal{C} 2021$ The Author(s): This is an open-access article distributed under the terms of the Creative Commons Attribution 4.0 International License (CC BY-NC 4.0) which permits unrestricted use, distribution, and reproduction in any medium for non-commercial use provided the original author and source are credited.

\section{INTRODUCTION}

Chondromas are benign tumors arising from the long bones, pelvis, or scapulae. Intracranial chondromas, however, are extremely rare [1]. Those at skull base are even rarer and their treatment is not sufficiently codified. Excision is the standard treatment and it must be complete [2]. However, this surgery is not always possible because of the richness in vasculonervous elements in this region. What justifies the use of radiation therapy.

We report in this work the case of a 60 -yearold woman, who presented with a skull base chondroma treated with radiation therapy alone. With a 2 years follow-up, a marked symptomatology improvement was reported by the patient. On control MRI, tumoral process remained stable.

We shed light, through this case, on the place of radiotherapy in the treatment of chondromas of skull base, as well as on its technical aspects.

\section{Case Report}

A 60-years-old female, with unremarkable past medical history, presented with three years' of dry eye on the left side, left hypo-acousia, left facial neuralgia and dizziness. Clinical assessment was normal, without any signs of physical or neurological deficits. A computed tomography (CT) scan showed a mass of the base of the skull, left lateralized, protruding into nasopharyngeal lumen, with intracranial extension. Brain magnetic resonance imaging (MRI) revealed a discreetly enhancing tumoral process of the skull base of $44 \times 46.5 \times 47.4 \mathrm{~mm}$, which extended to the infratemporal fossa, sphenoidal sinus, left cavernous sinus and left temporal lobe (Fig-1). Trans-nasal biopsy was performed and showed a proliferation of cartilaginous hyaline lobules, with regular chondrocytes and sometimes discrete atypies, without histological signs of malignancy, evoking a chondroma. Due to the surgical morbidity, radiation therapy management rather than surgical excision was adopted. 


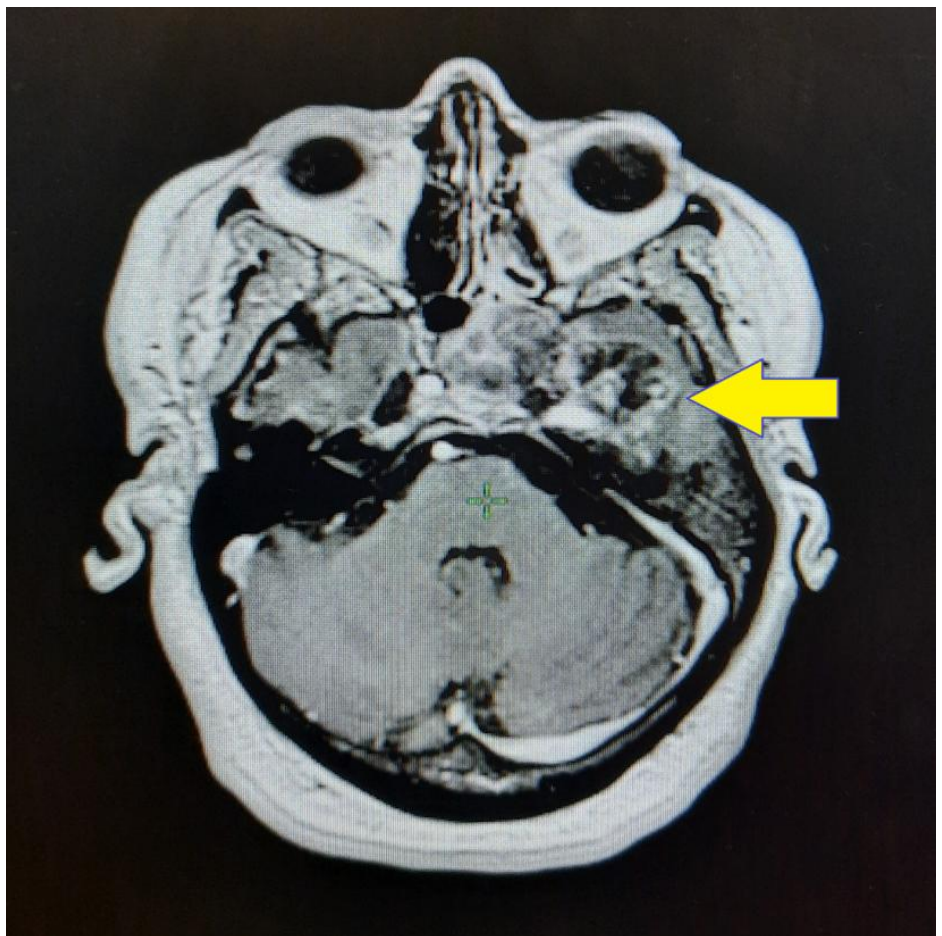

Fig-1: Axial slice of T2 weight brain magnetic resonance imaging, showing tumoral process of skull base, which extended to the infra-temporal fossa, sphenoidal sinus, left cavernous sinus and left temporal lobe

A CT-simulation was performed, the patient was positioned supine, thermoplastic mask was used for head immobilization. For delineation of target volume and organs at risk, a CT-MRI image registration was made. Clinical target volume (CTV) was defined as gross tumor volume (GTV) visualized on MRI with a 5 $\mathrm{mm}$ margin. CTV was expanded by $3 \mathrm{~mm}$ to generate planning target volume (PTV) (Fig-2). The patient was treated with dynamic conformal arc therapy using a single arc. A total dose of 50.4 Gray (Gy) was prescribed to the PTV in 28 fractions, five days a week. The PTV was covered by the $95 \%$ isodose volume, and maximum hot spots were $<110 \%$ (Fig-3). The treatment was well tolerated and no acute side effect was noted.

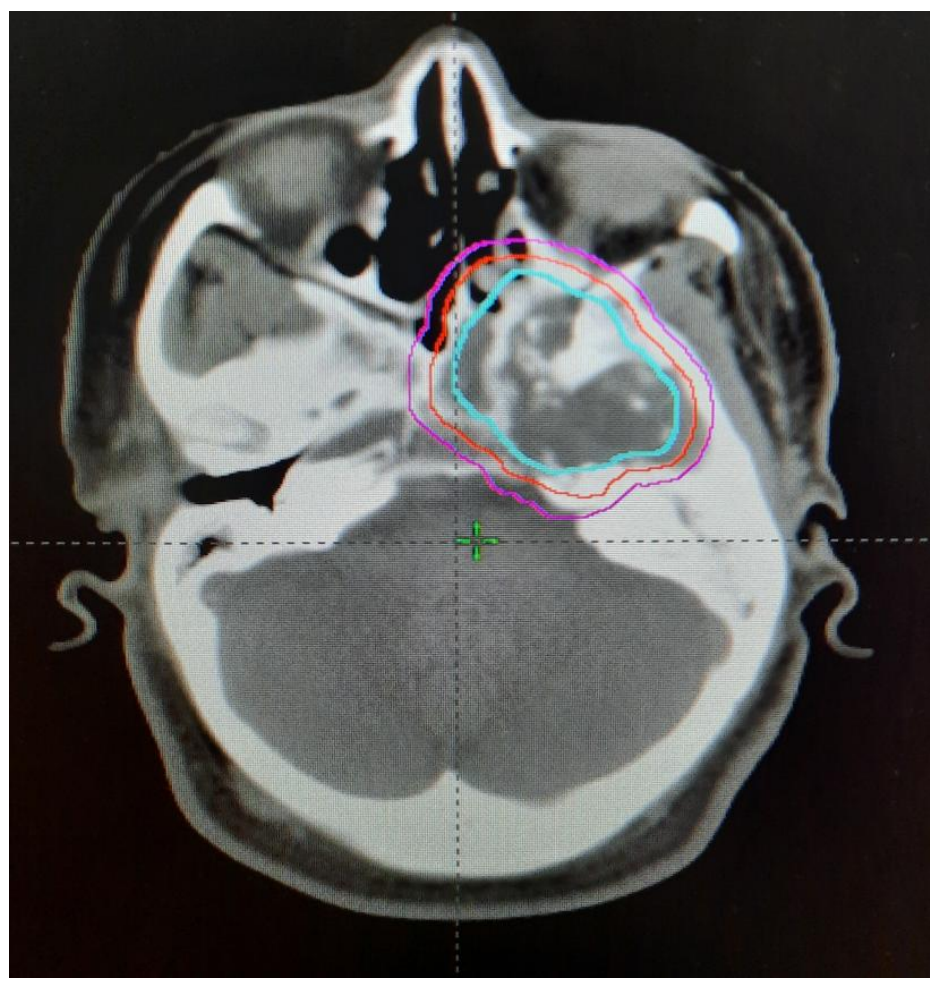

Fig-2: Axial CT-scan image from treatment planning system, showing delineation of Gross Target Volume (cyan), Clinical Target Volume (red), Planning Target Volume (magenta) 


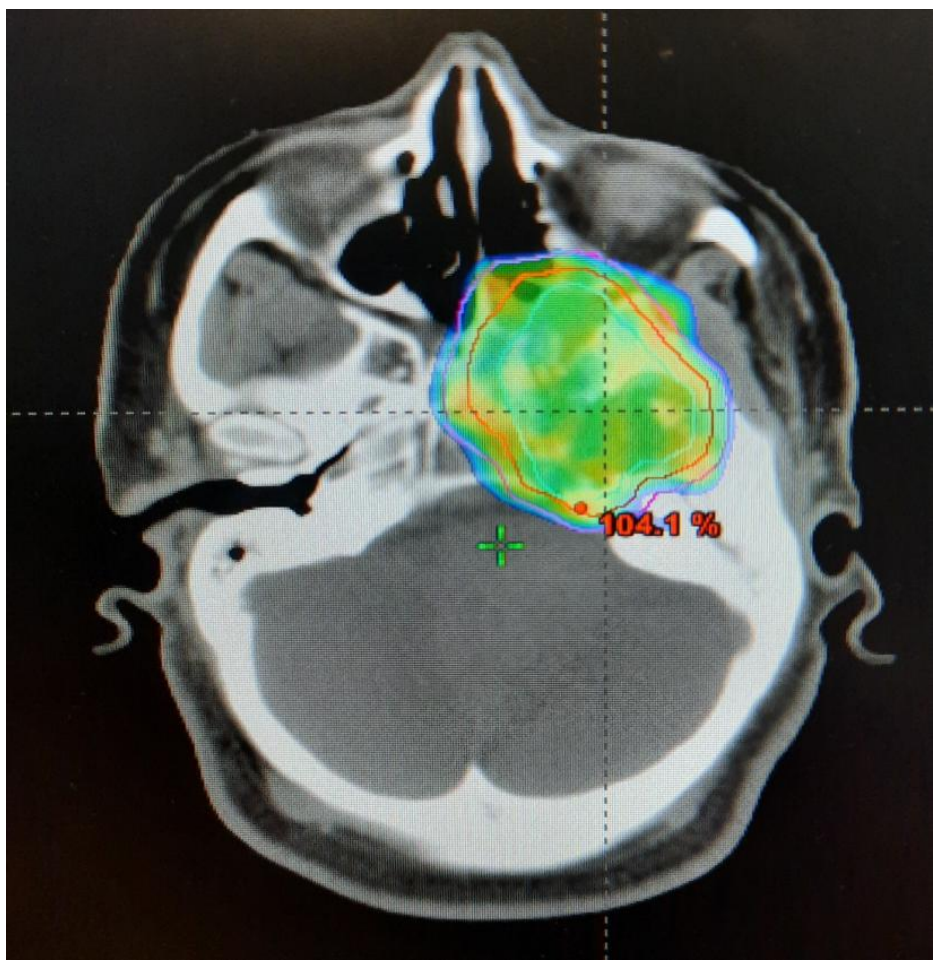

Fig-3: Axial CT-scan image from treatment planning system, showing dose distribution

With a 2 years follow-up, a marked symptomatology improvement was reported by the patient with disappearance of dizziness and facial neuralgia, and improvement of hypoacousia and dry eye. On control MRI, tumoral process remained stable.

\section{DiSCUSSION}

First described by Hirschfield in 1851 [1], intracranial chondroma is an extremely rare benign tumor, it represents approximately $0.06 \%$ to $0.3 \%$ of intracranial tumor [2]. These lesions usually arise at the base of the skull from embryonic chondrocytic cell remnants, but may also originate in the falx, and convexity dura [3]. A total of $70 \%$ to $80 \%$ of intracranial primary chondromas originate from the skull base and are located outside the endocranium. It usually occurs in the joint of basal skull, especially the side of the sellar area [4]. It usually occurs at the age of 20 to 60 years, the peak is about 30, and the incidence of occurrence is equal in both male and female sexes [5].

Patients with skull base chondroma, present with a long-standing history of signs and symptoms, which lack specificity. Symptoms caused by tumor are related to factors such as: site, size, involved nerves and cerebral vessels, and the eroded structure around. Majority of patients present dizziness, headache, nausea, and vomiting, which are caused by increased intracranial pressure. If the tumor oppresses brain tissue, nerve, and blood vessels around, the patient may present some symptoms of vision change, hearing loss, hemiplegia, epilepsy, and motor dysfunction of head and face. Even some mental symptoms will appear, such as changes in mood, character, and personality [6].

Computed tomography (CT) and magnetic resonance imaging (MRI) are the preferred diagnostic tools for the initial evaluation of patients with suspicion of skull base neoplasms [7]. CT general scanning shows high heterogeneous density lesion in base skull area. Tumor is lobulated, with clear border, with many ossification and calcification tissues. Non-calcified or cystoid area can be enhanced. In T1-weighted images, we can see that boundary of the tumor is clear and bone around the tumor is eroded, the tumor presents an unevenly low signal, whereas in T2-weighted images, the tumor presents an unevenly high signal, and the part of calcification and ossification tissues present low signal [5].

The diagnosis of primary chondroma in basal skull mainly depends on postoperative pathologic examination [8]. The diagnosis can be made on the basis of the biopsy, in the event of non-resectability, as is the case with our patient.

Complete resection is the treatment of choice when the lesion is amenable to total removal [3]. In the skull base, there are important vessels, nerves, and brain tissue. When surrounded by complex structure, the tumor often adheres to these important cranial nerves and vessels, and it is very difficult to resect it completely. That's why we opted to use radiotherapy to treat this chondroma. although some authors postulate that radiation therapy is not effective for chondroma 
A. Bazine et al., Sch J Med Case Rep, Feb, 2021; 9(2): 125-128

and a malignant transformation to chondrosarcoma has been reported after [9].

No recurrence is expected following complete resection of the tumor, and the long-term prognosis is good [10]. After radiation therapy or incomplete resection, risk of malignant transformation persists but it remains very low; of the order of $1 \%$ to $2 \%$ [11].

\section{Conclusion}

Skull base chondroma is a rare benign tumor. Complete surgical excision is the treatment of choice. In our case, we opted for radiation therapy given the complexity of vasculo-nervous relationships of the tumor, making resection very morbid and difficult. The results of radiotherapy are highly debated in the literature given the rarity of this anatomo-pathological entity.

\section{REFERENCES}

1. Kurt E, Beute GN, Sluzewski M, van Rooij WJ, Teepen JL. Giant chondroma of the falx. Case report and review of the literature. J Neurosurg 1996;85:1161-4.

2. Yeung JT, Krznarich TS, Moreno EA, Mukkamala A, Karim AS. Intracranial parafalcine chondroma in a pregnant patient. Surgical neurology international. 2012;3:44.

3. Heo J, Cho SJ. A case of giant skull base chondroma. Brain Tumor Res Treat. 2014;2(2):9295.
4. Gagné F, Copty M. Intracranial chondroma. Report of two cases and review of the literature. Canadian journal of neurological sciences. 1996 May;23(2):132-7.

5. Tang X, Li Z, Yin X, Zhao L. Skull Base Chondroma: A Case Report and Review of Literatures. Neurosurg Q. 2015; 25(1):70-73.

6. Daran SE, Gabarski SS, Hoff JT. Neurogical Surgery: A Comprehensive Reference Guide to the Diagnosis and Management of Neurosurgica1 Problem. 4th ed. Philadelphia. 1996:2998-23.

7. Welzel T, Meyerhof E, Uhl M, Huang K, von Deimling A, Herfarth K. Diagnostic accuracy of DW MR imaging in the differentiation of chordomas and chondrosarcomas of the skull base: a 3.0-T MRI study of 105 cases. Eur J Radiol. 2018 Aug;105:119-24.

8. Lv Hongbin, Jing Yan, Tipoe GL. Intracranial chondroma: bone morphogenetic protein in situ hybridization and quantitative analysis. J Pract Oncol. 2000; 15:254-256.

9. Grossman RI, Davis KR. Cranial computed tomographic appearance of chondrosarcoma of the base of the skull. Radiology. 1981; 141:403-8.

10. Mapstone TB, Wongmongkolrit T, Roessman U, Ratcheson RA. Intradural chondroma: a case report and review of the literature. Neurosurgery. 1983; 12:111-4.

11. Patel A, Munthali L, Bodi I. Giant cystic intracranial chondroma of the falx with review of literature. Neuropathology. 2009 Jun;29(3):315-7. 